\title{
The Effects of Oxidation Temperature on the Microstructure and Photocatalytic Activity of the $\mathrm{TiO}_{2}$ Coating
}

\author{
Xinxin TANG, Wusheng ZHA*, Guiyin ZHANG, Pengpeng LI, Jing TANG \\ College of Materials Science \& Engineering, Xihua University, Chengdu 610039 China \\ cross ${ }^{\text {ref }}$ http://dx.doi.org/10.5755/j01.ms.23.2.15590
}

Received 12 July 2016; accepted 01 December 2016

\begin{abstract}
Titanium coatings were prepared on the surface of $1 \mathrm{~mm} \mathrm{ZrO}_{2}$ balls by mechanical ball mill, then the coatings were oxidized to photocatalytic $\mathrm{TiO}_{2}$ films at $400 \sim 600{ }^{\circ} \mathrm{C}$. X-Ray Diffraction, Scanning Electron Microscope, Energy Dispersive Spectroscopy and Optical Microscope were used to analyze the microstructure and crystal form of the films. The photocatalytic activity of the samples was also evaluated. After that, the effects of oxidation temperature on the microstructure and photocatalytic activity of the films were discussed. The results show that the fabricated coatings are uneven, with average thickness of $60 \mu \mathrm{m}$. In the process of oxidation, oxygen is imported into the inner coatings by the gaps existed in the Ti coatings, which makes the Ti particles oxidize from surface to core, finally the films with $\mathrm{TiO}_{2}+\mathrm{Ti}$ composite microstructure are obtained. The films oxidized at $500{ }^{\circ} \mathrm{C}$ have the best photocatalytic performance with the degradation rate of methyl orange solution $79.08 \%$, this owing to the existence of anatase and the $\mathrm{TiO}_{2}+\mathrm{Ti}$ composite microstructure. The result will provide theoretical basis for the fabrication of efficient photocatalytic film. Keywords: mechanical ball milling, photocatalytic activity, $\mathrm{TiO}_{2}$, photocatalytic thin films, oxidation temperature.
\end{abstract}

\section{INTRODUCTION}

$\mathrm{TiO}_{2}$ is a kind of n-type semiconductor materials with a band gap of $3.2 \mathrm{eV}$ (anatase), it can be used in sewage treatment, air purification and other fields because of the high photocatalytic activity under ultraviolet irradiation [1-4]. Comparing with powder $\mathrm{TiO}_{2}$, supported $\mathrm{TiO}_{2}$ film photocatalyst can be easily recycled and reused, thus a large number of coating preparation technologies were used to fabricate $\mathrm{TiO}_{2}$ coatings (e.g., Physical Vapor Deposition, Chemical Vapor Deposition, Sol-Gel, and Magnetron Sputtering). Although these technologies are matured enough, complex operations and rigorous conditions are necessary. This is one of the reasons why $\mathrm{TiO}_{2}$ based sewage treatment method couldn't have a large scale application. Mechanical coating technology (MCT) is a new method to prepare thin films. The basic principle of MCT is the cold welding, which makes the particles adhere to the milling ball surface and form coatings when mechanical ball milling is processing. With a higher efficiency and a lower cost, MCT can be easily used to form coatings on spherical or cylindrical substrates such as balls or tubes [5-8]. It's no doubt that MCT provides new ideas to prepare supported $\mathrm{TiO}_{2}$ film, moreover, the prepared $\mathrm{TiO}_{2}$ coatings have a spherical appearance, which is good for photocatalytic reaction. Using MCT, Lu Yun has prepared $\mathrm{TiO}_{2}$ films on alumina balls and analyzed the formation mechanism of the films [8-11]. As for the oxidation process and the influence of oxidation temperature on photocatalytic activity of the $\mathrm{TiO}_{2}$ films, they didn't discuss deeply.

In this paper, $\mathrm{TiO}_{2}$ photocatalytic films were prepared on the surface of $\mathrm{ZrO}_{2}$ balls by MCT, and its photocatalytic activity was evaluated. The mechanism and rules of

\footnotetext{
* Corresponding author. Tel.: +8613688091585 .

E-mail address: $1434758301 @ q q . c o m$ (W. Zha)
}

oxidation process were studied, the influence of oxidation temperature on the microstructure and photocatalytic activity of $\mathrm{TiO}_{2}$ films was also investigated. The results are a great theoretical support for subsequently fabricating efficient photocatalytic film.

\section{EXPERIMENTAL DETAILS}

Titanium powder with $99.5 \%$ purity and an average diameter of $38 \mu \mathrm{m}$ was used as the coating metal, $\mathrm{ZrO}_{2}$ balls with an average diameter of $1 \mathrm{~mm}$ were used as substrates, because Ti coatings are easy to fabricate on the $\mathrm{ZrO}_{2}$ grinding balls. A planetary ball mill (ND7-2L) was employed to perform the mechanical coating operation, $57.14 \mathrm{~g} \mathrm{ZrO}_{2}$ balls and $20.86 \mathrm{~g}$ Ti powder were added into a $250 \mathrm{ml}$ alumina bowl. The rotation speed of the planetary ball mill was set at $300 \mathrm{r} / \mathrm{min}$ and the milling time was 15 hours. Then, the $\mathrm{ZrO}_{2}$ balls with $\mathrm{Ti}$ coating were oxidized in air at 400, 450, 500, 550, and $600{ }^{\circ} \mathrm{C}$ for $20 \mathrm{~h}$. Photocatalytic activity of the samples was evaluated by measuring the decomposition rate of methyl orange solution (water solution) at room temperature. $10 \mathrm{~g} \mathrm{ZrO}_{2}$ balls with titanium oxide films were added in $20 \mathrm{ml}$, volume concentration of $10 \mathrm{mg} / \mathrm{L}$ of methyl orange solution. The degradation rates of methyl orange solution under UV irradiation for $24 \mathrm{~h}$ were measured by the $721 \mathrm{~A}$ spectrometer. The wavelength of the spectrometer was set to $464 \mathrm{~nm}$, which is near the peak of absorption spectrum of methyl orange solution, as shown in Fig. 1. Before photocatalysis, all samples to be tested were put into dark to pre-adsorb for $12 \mathrm{~h}$. The surface morphologies and microstructures of the samples were observed by SEM (S3400), the element distribution was examined using an energy dispersive spectrometer being part of SEM. An optical microscope (DMM-400C) was used to observe the cross section of the coatings. An XRD (DMAX2500) with $\mathrm{Cu}-\mathrm{K} \alpha$ radiation at $25 \mathrm{kV}$ and $15 \mathrm{~mA}$ was used to analyze 
phase component, scanning speed $0.03 \%$, at range of $20 \sim 80^{\circ}$. The DSC curve of anatase was measured by STA449F3 DSC-TG thermal analyzer in Ar atmosphere at a heating rate of $20^{\circ} \mathrm{C} / \mathrm{min}$.

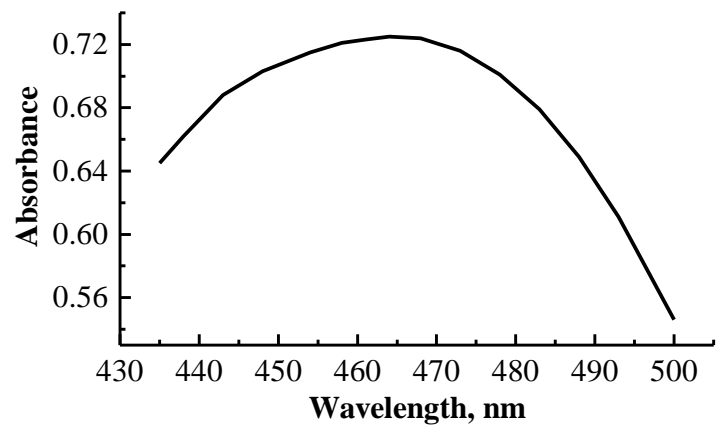

Fig. 1. The absorption spectra curve of methyl orange solution

\section{RESULTS AND DISCUSSION}

\subsection{Surface morphology and structure of coatings}

$\mathrm{ZrO}_{2}$ balls were mixed with $\mathrm{Ti}$ power and milled for $15 \mathrm{~h}$, and then the balls were oxidized in air at different temperatures. Fig. 2 shows the photograph of the samples. We can see that a continuous layer of metallic coating covered the ball surface at Fig. 2 a, however the metallic luster disappeared when the coatings were oxidized in air at different temperatures. With the increase of oxidation temperature, the color of coatings changed from dark blue to ash black (Fig. $2 \mathrm{~b}-\mathrm{f}$ ), which means that the oxidation results are different.

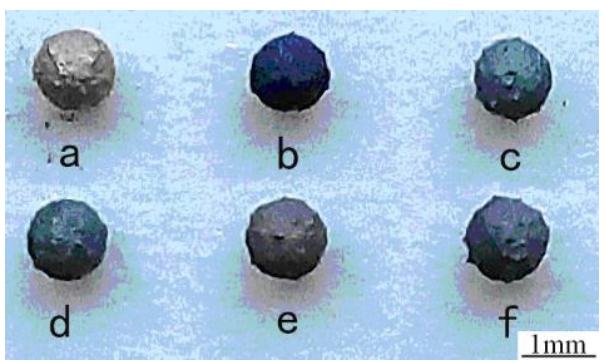

Fig. 2. Photograph of the samples fabricated by MCT and oxidized at: $\mathrm{a}$-room temperature; $\mathrm{b}-400{ }^{\circ} \mathrm{C} ; \mathrm{c}-450{ }^{\circ} \mathrm{C}$; $\mathrm{d}-500{ }^{\circ} \mathrm{C} ; \mathrm{e}-550{ }^{\circ} \mathrm{C} ; \mathrm{f}-600^{\circ} \mathrm{C}$

The surface SEM micrographs of the oxidized films are illustrated in Fig. 3. It's shown that the metal particles bond together and form flakes. Several flakes stack each other form coating. However, the coatings are not dense enough. Between and inside the flakes, there are a large number of pores and gaps. Oxidized at $400{ }^{\circ} \mathrm{C}$, the films have a low density as shown in Fig. 3 a, the flakes on the film's surface are out-of-shape and there are many pores in the films. But, with the increase of oxidation temperature, the flakes become smooth and the number of pores decrease, the films become more compact (Fig. $3 \mathrm{~b}-\mathrm{e}$ ). Because fine particles tend to agglomerate or bond together automatically in order to reduce surface energy, while, heating can intensify this process. Therefore, the sharp corners of the particles disappeared and the particles became flat, a bonding interface has formed between the particles after sintering.
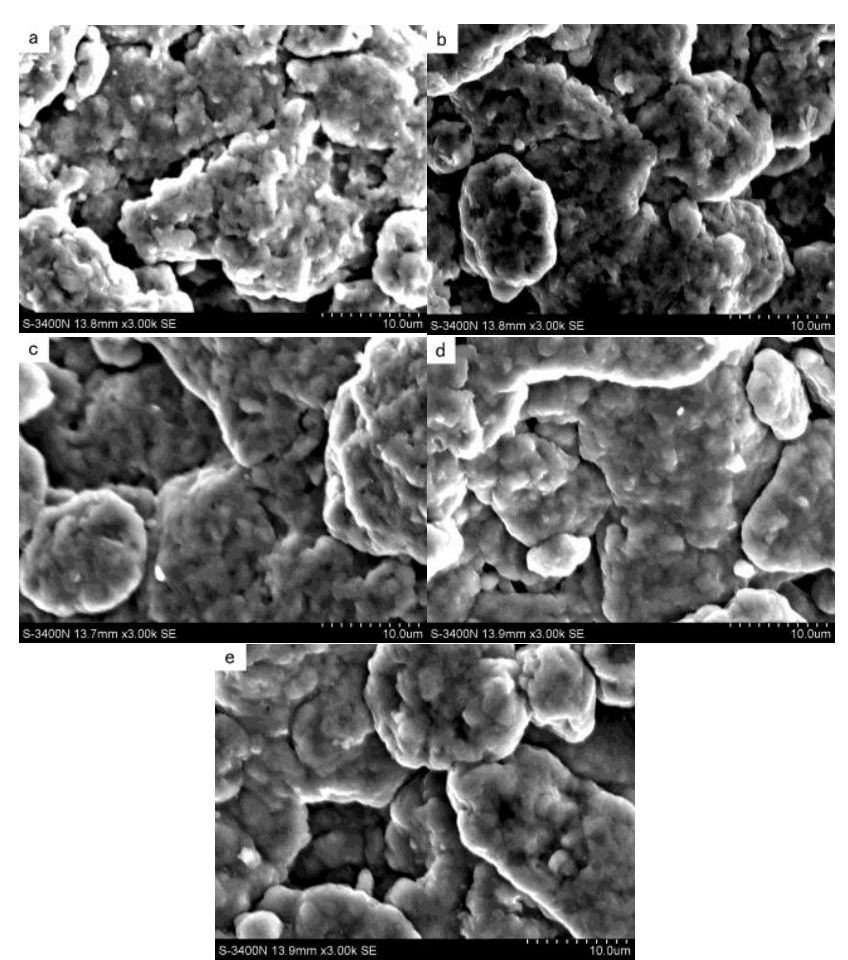

Fig. 3. SEM micrographs of the films oxidized in air for $20 \mathrm{~h}$ at: $\mathrm{a}-400{ }^{\circ} \mathrm{C} ; \mathrm{b}-450{ }^{\circ} \mathrm{C} ; \mathrm{c}-500{ }^{\circ} \mathrm{C} ; \mathrm{d}-550{ }^{\circ} \mathrm{C} ; \mathrm{e}-600{ }^{\circ} \mathrm{C}$

The optical micrographs of samples' cross section are shown in Fig. 4. Ball-milled for $15 \mathrm{~h}$, an uneven coating with average thickness of $60 \mu \mathrm{m}$ was formed on the surface of $\mathrm{ZrO}_{2}$ balls (Fig. 4 a).

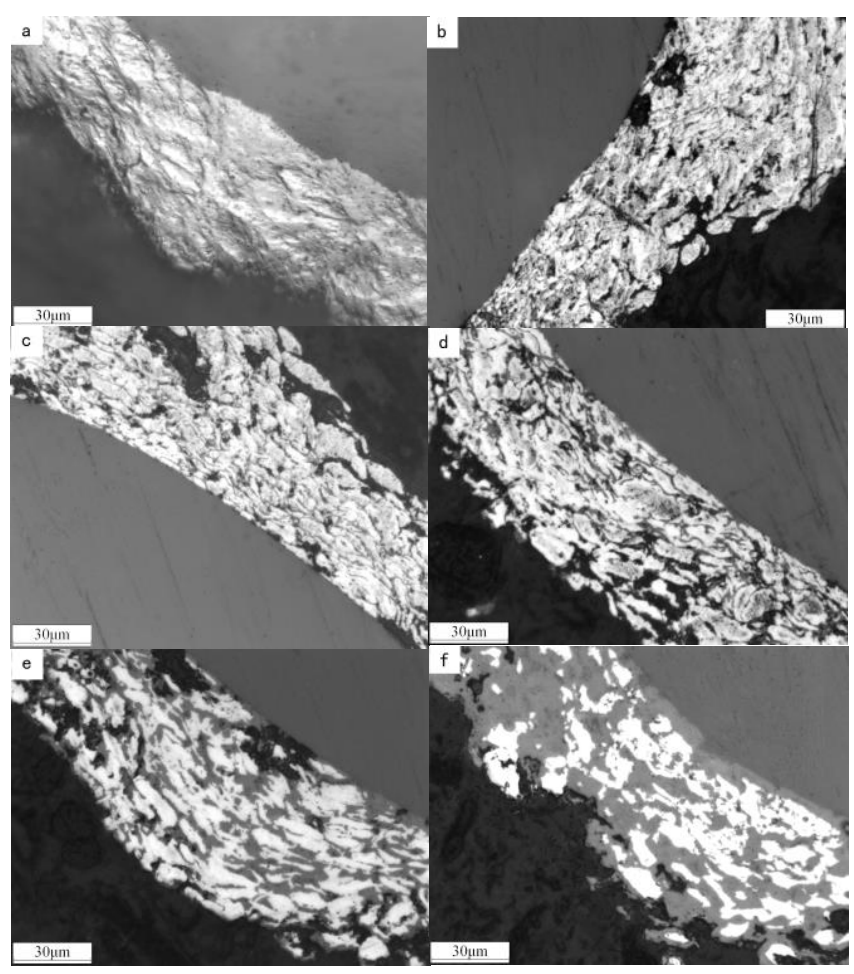

Fig. 4. Micrographs of the films' cross section oxidized in air for $20 \mathrm{~h}$ at: a-room temperature; b- $400{ }^{\circ} \mathrm{C} ; \mathrm{c}-450{ }^{\circ} \mathrm{C}$; $\mathrm{d}-500{ }^{\circ} \mathrm{C} ; \mathrm{e}-550{ }^{\circ} \mathrm{C} ; \mathrm{f}-600{ }^{\circ} \mathrm{C}$ 

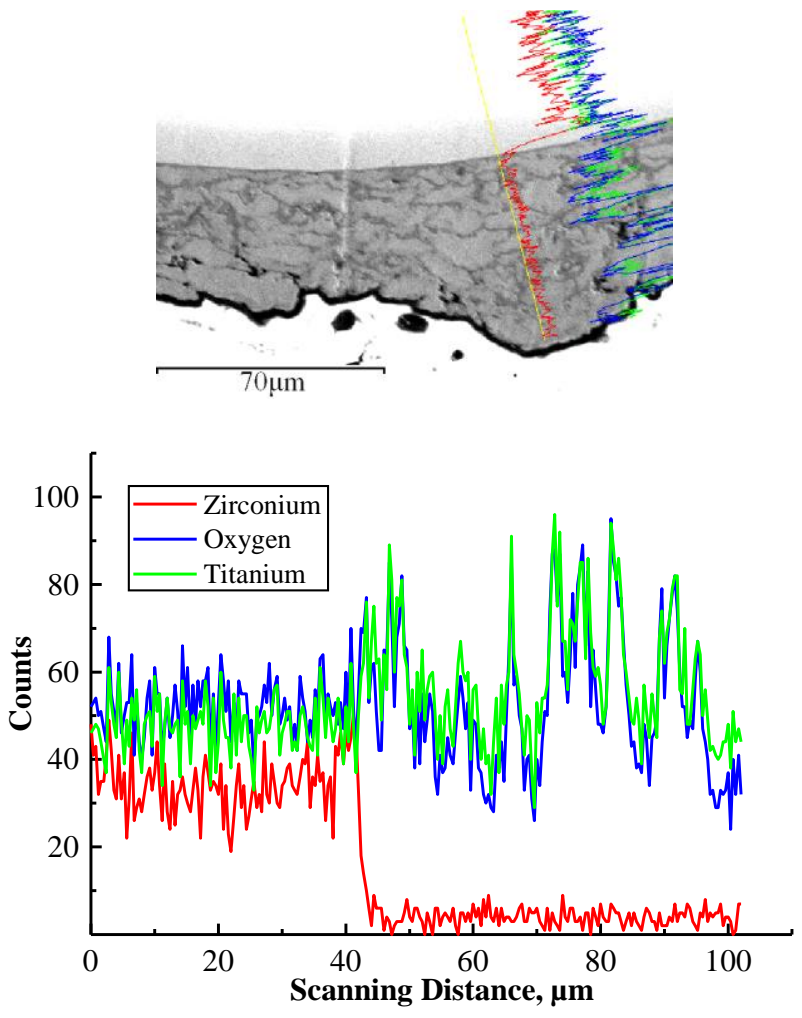

Fig. 5. EDS pattern of the film oxidized in air at $500^{\circ} \mathrm{C}$ for $20 \mathrm{~h}$

The bonding interface between coating and substrate is clear, which indicates that there is just mechanical bonding. And the interface among particles is inconspicuous. Oxidized at $400 \sim 600{ }^{\circ} \mathrm{C}$, the interface among particles become obvious, as shown in Fig. 4 b-d. A kind of gray new phase has been observed at the interface which is different from the interior of Ti particles. By linear SEMEDS (Fig. 5), it is found that the new phase is mainly composed of oxygen and titanium, which infers that the new phase is titanium oxide. As shown in Fig. 4, with oxidation temperature increasing, the white Ti areas shrink; the gray oxide areas enlarge, and reach to the maximum at $600{ }^{\circ} \mathrm{C}$. The results indicate that the oxidation starts at the surface of each particle in the coatings, and penetrates into the interior. In the coatings, there are many tiny gaps between the Ti particles, so, oxygen can enter the coating internal through the gaps, as a result, oxidation does not just start at the outermost layer, not only the Ti particles on the outer layer but also the inner ones contact with oxygen and will be oxidized.

\subsection{Phase composition of the films}

Fig. 6. shows XRD patterns of the films oxidized at different temperatures for $20 \mathrm{~h}$. The diffraction peaks of $\mathrm{ZrO}_{2}$ can not be detected, which suggests that the prepared films are continuous and thick enough, $\mathrm{X}$ ray can't penetrate it. When the oxidation temperature is below $500{ }^{\circ} \mathrm{C}$, the films consist of $\mathrm{Ti}$ and a little titanium oxide, and only a small amount of $\mathrm{Ti}$ was oxidized. With the increase of oxidation temperatures, the intensity of $\mathrm{Ti}$ peaks decrease (PDF2: 89-5009), while that of rutile peaks increase at $2 \theta$ of about $28^{\circ}$ and $70^{\circ}$ (PDF2: 87-0710). Oxidized at $600{ }^{\circ} \mathrm{C}$, the Ti peaks still exist at about $40^{\circ}$, which indicates that the particles have not been oxidized completely under this condition, this is consistent with what have been observed in Fig.4. Although the intensity is weak, the diffraction peaks of anatase $\mathrm{TiO}_{2}$ appear at about $25^{\circ}$ and $37^{\circ}$ (PDF2: 71-1168) when oxidized at $500{ }^{\circ} \mathrm{C}$, which shows that there is a little anatase $\mathrm{TiO}_{2}$ in the film. With the temperature rising, the content of anatase gradually decreases, as a result, the anatase $\mathrm{TiO}_{2}$ peaks couldn't be detected in the films oxidized at $550{ }^{\circ} \mathrm{C}$ and $600{ }^{\circ} \mathrm{C}$.

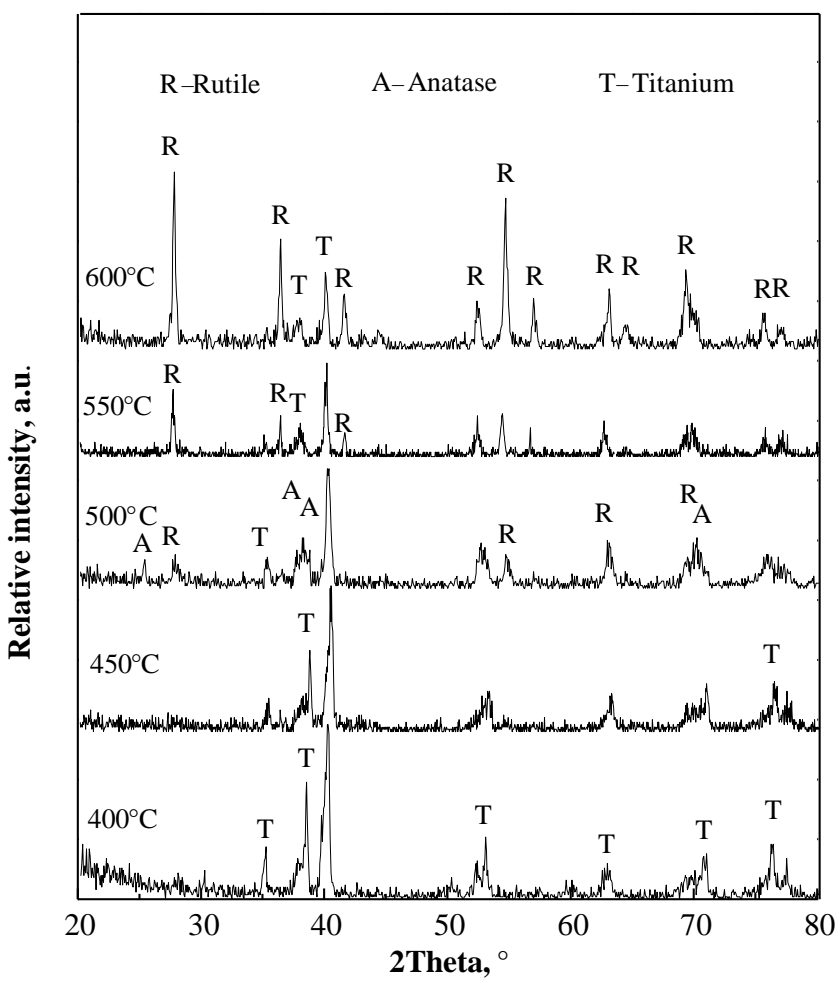

Fig. 6. XRD patterns of films oxidized in air at different temperatures

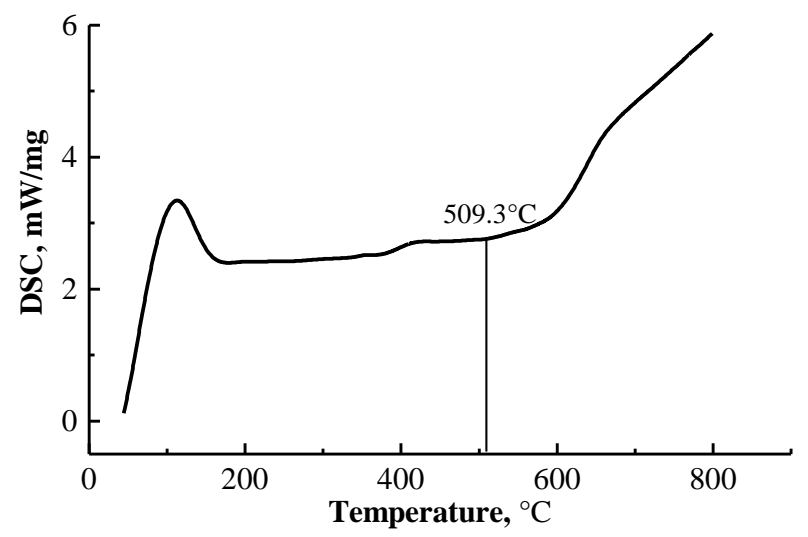

Fig. 7. DSC pattern of anatase powder

Because anatase $\mathrm{TiO}_{2}$ is a kind of metastable phases and will transform to rutile $\mathrm{TiO}_{2}$ as the temperature rises. Fig. 7 shows the DSC curve of anatase. It can be seen that the transformation from anatase to rutile started at about $509.3^{\circ} \mathrm{C}$. So when the samples were oxidized at $550{ }^{\circ} \mathrm{C}$ and $600{ }^{\circ} \mathrm{C}$, anatase reduced and its diffraction peaks disappeared in relevant XRD patterns. Thus, it can be 
concluded that, oxidized at $400 \sim 600{ }^{\circ} \mathrm{C}$, the films with $\mathrm{TiO}_{2}+\mathrm{Ti}$ composite microstructure are obtained and $\mathrm{TiO}_{2}$ mainly exist in rutile. After oxidized at $500{ }^{\circ} \mathrm{C}$, there is a little anatase $\mathrm{TiO}_{2}$ in the films, but does not at above $500{ }^{\circ} \mathrm{C}$.

\subsection{Photocatalytic activity}

Fig. 8 shows the dependence of methyl orange solution degradation rate on the oxidation temperature. We can see that the degradation rate increases with the oxidation temperature increase below $500{ }^{\circ} \mathrm{C}$, but it decreases beyond $500{ }^{\circ} \mathrm{C}$. Oxidized at $500{ }^{\circ} \mathrm{C}$, the films have the best photocatalytic performance with a degradation rate of methyl orange solution $79.08 \%$. Below $500{ }^{\circ} \mathrm{C}$, the coatings can't be oxidized sufficiently and there still exists much more Ti. But, as the temperature rises up, the content of $\mathrm{TiO}_{2}$ increases and the photocatalytic activity is enhanced relatively.

It's well known that anatase $\mathrm{TiO}_{2}$ has more crystal defects and dislocations than rutile, which leads to an easier separation of photogenerated electron-hole pairs, and the electron hole produced by anatase is easier to be captured, besides, anatase has a stronger adsorption ability to the organic matter. So the photocatalytic performance of anatase $\mathrm{TiO}_{2}$ is significantly better than that of rutile $[12,13]$. When oxidized at $500{ }^{\circ} \mathrm{C}$, the $\mathrm{TiO}_{2}+\mathrm{Ti}$ composite microstructure has been obtained, according to the publication, the $\mathrm{TiO}_{2}+\mathrm{Ti}$ composite microstructure is benefit for the separation of photogenerated electron-hole pairs at the surface of $\mathrm{TiO}_{2}$, thus it can improve the photocalatytic activity $[14,15]$. On the other hand, oxidized at this temperature, some $\mathrm{TiO}_{2}$ exists as anatase phase, which is also a great increase in photocatalytic activity, therefore the films oxidized at $500{ }^{\circ} \mathrm{C}$ have the best photocatalytic performance. However, with the further increase of oxidation temperature, the content of $\mathrm{TiO}_{2}$ increased, correspondingly that of $\mathrm{Ti}$ decreased, and anatase $\mathrm{TiO}_{2}$ transformed to rutile type at $500 \sim 600{ }^{\circ} \mathrm{C}$.

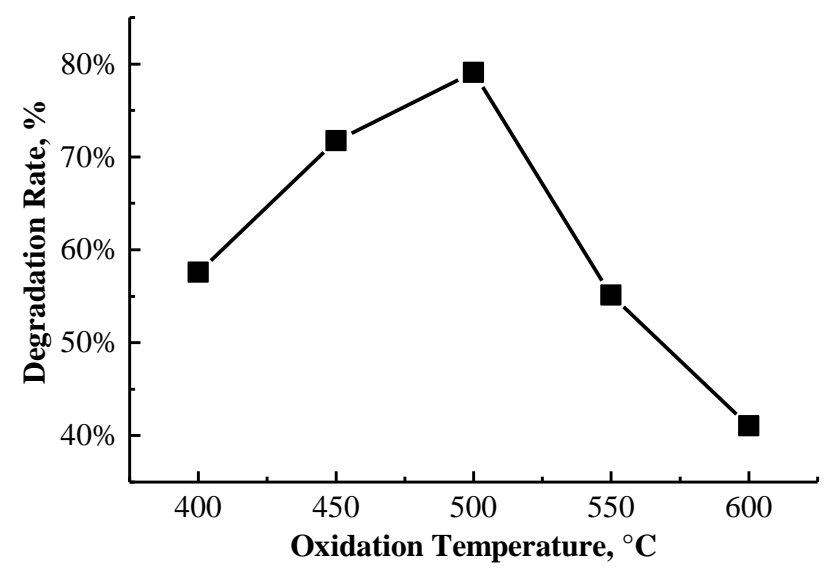

Fig. 8. Dependence of methyl orange solution degradation rate on the oxidation temperature

Oxidized at $600{ }^{\circ} \mathrm{C}$, the formed $\mathrm{TiO}_{2}$ layer is so thick that the photogenerated electron-hole pairs have been blocked and couldn't been separated effectively, which finally leads to the worst photocatalytic performance with the degradation rate of $41.06 \%$.

\section{CONCLUSIONS}

1. The coatings prepared by MCT have an average thickness of $60 \mu \mathrm{m}$. A large number of gaps exist in the metallic coating. Oxidation didn't just start at the outermost layer, oxygen could enter the inner coating through these gaps, which leads to the Ti particles in the coatings gradually being oxidized from the surface to the core.

2. $\mathrm{TiO}_{2}+\mathrm{Ti}$ composite microstructure has been obtained when the coatings are oxidized at $400 \sim 600{ }^{\circ} \mathrm{C}$, the higher the oxidation temperature, the higher the $\mathrm{TiO}_{2}$ content. $\mathrm{TiO}_{2}$ mainly exists in rutile type, but oxidized at $500{ }^{\circ} \mathrm{C}$, the films contain a small amount of anatase $\mathrm{TiO}_{2}$.

3. The films prepared at $400 \sim 600{ }^{\circ} \mathrm{C}$ have different photocatalytic performance, oxidized at $500{ }^{\circ} \mathrm{C}$, the films have the best photocatalytic performance with the degradation rate of $79.08 \%$, due to the $\mathrm{TiO}_{2}+\mathrm{Ti}$ composite microstructure and the existing of anatase $\mathrm{TiO}_{2}$.

\section{Acknowledgments}

I thank Prof. Liu Jinyun reading my manuscript and helpful suggestion. This work was supported by the Education Department of Sichuan Province (16201452) and Graduate Innovation Fund of Xihua University (ycjj2015109 "Preparation of $\mathrm{NiO}-\mathrm{TiO}_{2}$ composite photocatalyst films by mechanical ball mill method")

\section{REFERENCES}

1. Carp, O., Huisman, C.L., Reller, A. Photoinduced Reactivity of Titanium Dioxide Progress in Solid State Chemistry $32(1-2)$ 2004: pp. 33-177. http://dx.doi.org/10.1016/j.progsolidstchem.2004.08.001

2. Shen, X.Z., Liu, Z.C., Xie, S.M., Guo, J. Degradation of Nitrobenzene Using Titania Photocatalyst Co-Doped with Nitrogen and Cerium Under Visible Light Illumination Journal of Hazardous Materials $162(2)$ 2009: pp. $1193-1198$. http://dx.doi.org/10.1016/j.jhazmat.2008.06.004

3. Asahi, R.Y.O.J.I., Morikawa, T.A.K.E.S.H.I., Ohwaki, T., Aoki, K., $\quad$ Taga, Y. Visible-Light Photocatalysis in Nitrogen-Doped Titanium Oxides Science 293 (5528) 2001: pp. 269-271. http://dx.doi.org/10.1126/science.1061051

4. Zhang, X., Liu, Q. Preparation and Characterization of Titania Photocatalyst Co-Doped With Boron, Nickel, And Cerium Materials Letters 62 (17) 2008: pp. 2589-2592. http://dx.doi.org/10.1016/j.matlet.2007.12.061

5. Revesz, A., Takacs, L. Coating Metals by Surface Mechanical Attrition Treatment Journal of Alloys and Compounds 441 (1) 2007: pp. 111-114. http://dx.doi.org/10.1016/j.jallcom.2006.09.081

6. Zadorozhnyy, V., Kaloshkin, S., Kaevitser, E., Romankov, S. Coating of Metals with Intermetallics by Mechanical Alloying Journal of Alloys and Compounds 509 (509) 2011: pp. S507-S509. http://dx.doi.org/10.1016/j.jallcom.2011.01.164 
7. Zadorozhnyy, V., Kaloshkin, S., Tcherdyntsev, V., Gorshenkov, M., Komissarov, A., Zadorozhnyy, M. Formation of Intermetallic Ni-Al Coatings by Mechanical Alloying on the Different Hardness Substrates Journal of Alloys and Compounds 586 (6) 2014: pp. S373-S376. http://dx.doi.org/10.1016/j.jallcom.2013.03.263

8. Lu, Y., Hirohashi, M., Zhang, S. Fabrication of Oxide Film by Mechanical Coating Technique International Conference on Surfaces, Coatings and Nanostructured Materials (nanoSMat2005) Sep. 7-9th, 2005, Aveiro, Portugal, pp. No. FP117.

9. Yoshida, H., Lu, Y., Nakayama, H., Hirohashi, M. Fabrication of $\mathrm{TiO}_{2}$ Film by Mechanical Coating Technique and Its Photocatalytic Activity Journal of Alloys and Compounds 475 (1) 2009: pp. 383-386. http://dx.doi.org/10.1016/j.jallcom.2008.07.059

10. Lu, Y., Guan, S., Hao, L., Yoshida, H. Review on the Photocatalyst Coatings of TiO2: Fabrication by Mechanical Coating Technique and Its Application Coatings 5 (3) 2015: pp. $425-464$. http://dx.doi.org/10.3390/coatings5030425

11. Lu, Y., Hao, L., Kobayashi, K., Sato, H., Yoshida, H., Guan, S.J., Chen, J.X. Fabrication and Photocatalytic Activity of Photocatalyst Coatings by Mechanical Coating Technique and the Oxidation at Relatively Low
Temperatures Applied Mechanics and Materials 719-720 2015: pp. 17-20.

http://dx.doi.org/10.4028/www.scientific.net/AMM.719-720.17

12. Fujishima, A., Zhang, X., Tryk, D.A. $\mathrm{TiO}_{2}$ Photocatalysis And Related Surface Phenomena Surface Science Report 63 (12) 2008: pp. 515-582. http://dx.doi.org/10.1016/j.surfrep.2008.10.001

13. Zhang, J., Xu, Q., Feng, Z., Li, M., Li, C. Importance of the Relationship Between Surface Phases and Photocatalytic Activity of $\mathrm{TiO}_{2}$ Angewandte Chemie International Edition 47 (9) 2008: pp. $1766-1769$. http://dx.doi.org/10.1002/anie.200704788

14. Lu, Y., Matsuzaka, K., Hao, L., Hirakawa, Y., Yoshida, H., Pan, F.S. Photocatalytic Activity of $\mathrm{TiO}_{2} / \mathrm{Ti}$ Composite Coatings Fabricated by Mechanical Coating Technique and Subsequent Heat Oxidation Materials Science in Semiconductor Processing 16 (6) 2013: pp. $1949-1956$. http://dx.doi.org/10.1016/j.mssp.2013.07.024

15. Lu, Y., Yoshida, H., Toh, K., Hao, L., Hirohashi, M. Performance Improvement of $\mathrm{TiO} / \mathrm{Ti}$ Composite Photocatalyst Film by Heat Oxidation Treatment In Materials Science Forum 675 2011: pp. 1233-1236. http://dx.doi.org/10.4028/www.scientific.net/MSF.675677.1233 